\title{
Community Benefit from Tourism: Myth or Reality A Case Study of the Soshanguve Township
}

\section{Acha-Anyi Paul Nkemngu*}

Department of Tourism Management, Tshwane University of Technology, South Africa

\begin{abstract}
Community participation and benefit from tourism ventures is generally regarded as the cornerstone of sustainable tourism. Hence, the gains from tourism have been heralded as instrumental in the fight against poverty and helping to uplift disadvantaged communities through the provision of access to economic and social benefits. Paradoxically, tourism literature equally alludes to instances in which tourism has stripped local communities of their natural resources, desecrated their cultural heritage and degraded their social structures.

This study assesses the perceptions of the residents of the Soshanguve community, a township in the outskirts of Pretoria, with regards to the contribution of tourism to the development of their community. The impact variables considered are economic, socio-cultural and environmental, while investigating the effect, if any, that community attachment has on the perceptions of the community members.

The quantitative research method was employed through the use of a questionnaire to collect data from community members with some interest in tourism. Results reveal that most community members do not perceive tourism to have contributed significantly to the development of their community. Also noticeable from the results is the negative co-relation between community attachment of the respondents and the perception that tourism has failed to contribute to a better quality of life for community members.

This research has far-reaching implications for tourism sustainability as the local communities are major stakeholders in tourism development. It also points to the necessity to prepare communities well in advance of tourism development. Tourism planners and developers should adopt a bottom-top approach rather than the reverse. With many tourists seeking the local experience and desiring to have close contact with the local people, it has become an imperative for local people to be involved in tourism development from the planning stage. Tourism education among community members should begin as soon the idea to include tourism in the strategic development plan is conceived. This calls for effective stakeholder participation in the tourism planning and development process
\end{abstract}

\section{Introduction}

Sustainable development and its derivative sustainable tourism development have gained prominence in literature in recent times because it is believed such development would not only be attractive to tourists but equally enhance opportunities for local economic growth and improve the quality of life of residents, while safeguarding opportunities for future generations by ensuring the sustainable co-existence of tourism and the environment $[1,2]$. The realization of the foregoing necessitates a participatory approach to tourism development by creating avenues for local residents to participate and benefit from tourism development [3]. This approach will encourage the local people to adopt a more positive attitude towards tourism and further ensure the conservation of tourism resources [4]. Social exchange theory reinforces this paradigm by indicating that the decision by local residents to embrace tourism development is a result of the community's weighting of the perceived economic, social, cultural and environmental benefits and costs emanating from tourism development [5-7], hence if the host residents perceive the positive impacts of tourism to outweigh the costs, then these residents are likely to support and participate in community-based tourism development $[8,9]$.

The benefits of using tourism as a strategy for local economic development (LED) have been largely publicized in literature, with references to benefits accruing from foreign exchange earnings, employment creation and the stimulation of the local economy among others $[10,11]$. As a result, many governments, especially in countries with low gross domestic product (GDP) have invested a substantial amount of tax revenue in the development of tourism [11]. This general sense of optimism is founded on the positive trends and forecasts registered in the tourism industry during the past decade. According to the World Travel and Tourism Council [12], travel and tourism industry direct contribution to global GDP stood at US\$ 6,346.1 billion (9.1\% of GDP) in 2011 and is forecast to grow by $2.8 \%$ in 2012 and rise by $4.3 \%$ per annum to USD9, 939.5 billion by 2022 . South Africa has not been left behind in reaping the fruits of this tourism bonanza as the country enjoyed an increase of $4.8 \%$ in total tourism contribution to GDP constituting ZAR328.2 bn (11.4\% of GDP) in 2011. During the same period, tourism supported 594,000 direct jobs (4.5\% of total employment) [13].

This study seeks to establish the extent to which local residents in the community of Soshanguve perceive the benefits of tourism development to have filtered into their community. Soshanguve is a township about thirty kilometers from the Pretoria city centre. The

*Corresponding author: Acha-Anyi Paul Nkemngu, Department of Tourism Management, Tshwane University of Technology, Pretoria, South Africa, Tel: 0027(0)-72-589-8973; Fax: 0027-(0)-12-382-4611; E-mail: acha-anyipn@tut.ac.za; or achaseatt@gmail.com

Received July 20, 2012; Accepted October 27, 2012; Published October 31 2012

Citation: Paul Nkemngu AA (2012) Community Benefit from Tourism: Myth or Reality A Case Study of the Soshanguve Township. J Tourism Hospit 1:105 doi:10.4172/2167-0269.1000105

Copyright: (c) 2012 Paul Nkemngu AA. This is an open-access article distributed under the terms of the Creative Commons Attribution License, which permits unrestricted use, distribution, and reproduction in any medium, provided the original author and source are credited. 
economy of this local community is dominated by informal petty trading with most people formally employed commuting either to the industrial area of Rosslyn (about 15 kilometers away) or in the Pretoria Central Business District (CBD). The community can boast of a few tourist attractions notably the Tswaing crater, the Soshanguve plaza mall, Tshwane University of Technology campuses among others. There is a local tourism association known as the Soshanguve Tourism Forum (STF) with tourism business clusters such as art and craft, Bed and Breakfasts, tour operators, and so on. These were the principal respondents to this questionnaire whose goal was to capture their perceptions on the benefits of tourism to their community.

\section{Background}

With the advent of democracy in 1994, one of the immediate priorities of the new democratic government was to improve the quality of life of the poor, generally black population by developing policies that would facilitate access to economic opportunities. The goal, as mentioned in several policy documents including the integrated Rural Development Strategy [14] was to redress the socio-economic imbalances created by the apartheid government and eliminate poverty and unemployment by the year 2020. This new dispensation was designed to empower local people to take active part in matters affecting their future and determine the development process within their communities [15].

In conformity with the new policy shift, tourism policy framework documents have been formulated since 1994 to reposition tourism to assume and play its role in the democratic South Africa [16]. Notable among the tourism policy documents is the White paper on the Development and Promotion of Tourism in South Africa [17] and the Tourism in GEAR (Growth, Employment and Redistribution) strategy document [18]. The tourism vision set out in the White paper seeks to among other things, to develop tourism as a national priority in a sustainable manner and use it as a tool to fast-track development in rural communities and ensure balanced development for all South Africans. While, the White paper deals with policy issues, the tourism in GEAR document forges a framework for the implementation of these policies in the macro-economic context [19]. According to Rogerson and Visser, both documents advocate a collaborative approach to tourism development with the government taking the lead and the private sector driving the industry with sensitivity to local community development needs. The Responsible Tourism Handbook: A Guide to Good Practice for Tourism Operators [20] further elaborates on how opportunities for local communities should be prioritized in tourism.

The development of township tourism as a niche is characteristic of the post apartheid South Africa with the democratic transition in 1994. Prior to this period heritage tourism in South Africa was synonymous with "White heritage" as it showcased exclusively the origins, past and interests of the country's white minority [21]. A further impediment to the development of tourism in the townships before 1994 was the fact that many black neighborhoods were considered "no go" areas for people of other races because of the high levels of violence [22]. However, the smooth political transition and the subsequent development of the South Africa tourism economy have availed opportunities for tourism development in the black dominated communities. A number of townships have therefore capitalized on these opportunities, not only to recount the stories of their epic struggle against apartheid but also to develop other service industries such as bed and breakfasts (B \& Bs), and township tours [23,24]. According to Goudie et al. [21] the Black spaces in South Africa have gone largely unrecognized and have therefore been excluded from opportunities to participate or partner in tourism ventures. The growth of township tourism has therefore opened up access to sites of significance to antiapartheid activists and also given the world an understanding of the poverty issues plaguing the formally oppressed communities in South Africa. This is the motivation of this study which investigates the extent to which residents of the township of Soshanguve perceive tourism gains to have filtered down to their community.

\section{Soshanguve Township}

Even though the history of human habitation in the area known today as Soshanguve can be traced as far back as 200, 000 years ago, the creation of the township with its name as it is known today is as recent as 1972 [25]. The township owes its name "Soshanguve" to the mixture of ethnic groups that the apartheid government forcibly re-located to this area in 1972, namely; Sotho, Shangaan, Nguni and Venda, hence "So" for Sotho, "Shan" for Shangaan, "Gu" for Nguni and "Ve" for Venda.

Some of the prominent people to have influenced the history of the Soshanguve community and placed it in the limelight, are Father Smangaliso Mkhatshwa and Dr. George Mkhari. Banished from the Transkei by the apartheid government, Father Smangaliso later became a member of parliament in post-apartheid South Africa in 1994 and the mayor of the city of Pretoria subsequently. Dr. George Mkhari on the other hand, set up a practice in which many activists injured in the anti-apartheid riots were treated free of charge

\section{Economic and Tourism Environment}

Gauteng, the province in which Soshanguve Township is located, is the smallest but most strategic province of South Africa considering its economic and political prowess. Apart from being the richest province in the country, Gauteng boasts of hosting two major geographical tromp cards: the main access way into South Africa (O. R. Tambo international airport in Johannesburg), and the capital city of the country, Pretoria. According to the Gauteng Tourism Authority (annual report 2010/2011), [26] the province's tourism market share grew by 20.6 percent in 2010 to 49.4 percent. The number of international tourists' arrivals increased from 3.3 million in 2009 to 3.9 million in 2010 .

Soshanguve is one of the many townships surrounding Pretoria or Tshwane, the capital of South Africa. In addition, two of the top ten international attractions in South Africa, Gold Reef city and Sun City are in close proximity to Pretoria. One would naturally expect townships like Soshanguve to benefit substantially from being close to these flagship attractions. More so, SOWETO, one of the townships around Johannesburg has a fairly successful model of township tourism from which other townships like Soshanguve could copy. The question then arises as to why this is not the case?

The population of Soshanguve was projected in 2006 to stand at 509, 094, with a fairly balanced gender distribution of 51.1 percent males and 49.8 percent females. According to GPS architects [25], 14 percent of the population has attained tertiary education, 45.5 percent secondary education, 29.9 percent secondary education and 10.6 percent of the population does not have any formal education. Infrastructure development is quite good with 53.1 percent of the population having access to telephone connections in their homes, 80 percent electricity, 96.9 percent sanitation and 90.2 percent having electricity. With a workforce of 11,651 people, only 44.7 percent of the population is employed, leaving 55.3 percent unemployed. 
Only one of the things mentioned "To do" or "To see" on the Gauteng Tourism Authority website is in Soshanguve. This is the Tswaing meteorite crater. This leaves one wondering as to why the townships with their rich cultural and historical significance are not publicized.

\section{Literature Review}

\section{Community tourism}

Hall [27] describes tourism as an expression of lifestyle "identified either through voluntary travel or a voluntary temporary short-term change of residence". The motives of such travel are increasingly wideranging, including among others education, business, health and leisure. Following on this, Cooper et al. [28] indicate that the core elements of tourism arise out of the movement of people to and their stay in various destinations outside their usual environments and places of work. This in-turn fuels the demand for various facilities and services designed to provide for and ease the transition and temporary residence of visitors in the host community. The supply of direct and support services such as transport, accommodation, catering, souvenirs and other shopping to tourists should help stimulate the local economy, create jobs, bring additional income and hence improve the quality of life of community members.

In this light, Spenceley [29] defines community tourism as "tourism which is owned and/or managed by communities with the aim of generating wider community benefit". Choi and Sirakaya [30] further argue that the main aim of community tourism should be to improve the residents' quality of life by maximizing local economic benefits, protecting the natural and built heritage and providing a high quality of experiences for the visitors. However, taking a slightly different view, Petric emphasizes that community tourism should aim at giving visitors personal contact with the physical and human environment of the countryside and allow them to participate in the activities, traditions and lifestyles of the local people.

\section{Sustainable tourism}

The concept of sustainability gained prominence after the publication of the World Commission on Environment and Development (WCED) report "Our Common Future" which defined Sustainable Development as development that "Meets the needs of the present without compromising the ability of future generations to meet their own needs" [31,32] points out that the attainment of sustainable development necessitates a balance between economic efficiency, environmental integrity and social justice. According to Butler [33], sustainable tourism refers to "Tourism which is developed and maintained in an area (community or environment) in such a manner and at such a scale that it remains viable over an infinite period and does not degrade or alter the environment (human or physical) in which it exists to such a degree that it prohibits the successful development and well being of other activities and processes". The United Nations World Tourism Organization's (UNWTO) [34] provides a comprehensive definition of sustainable tourism development when it states that sustainable tourism development "meets the needs of present tourists and host regions while protecting and enhancing opportunity for the future. It is envisaged as leading to management of all resources in such a way that economic, social and aesthetic needs can be fulfilled while maintaining cultural integrity, essential ecological processes, and biological diversity, and life support systems".

\section{Tourism and sustainable community development}

The study of tourism business development has gained impetus in recent times. According to Lee \& Chang [11] "A general consensus has emerged that it [tourism] not only increases foreign exchange and incomes, but also creates employment opportunities, stimulates the growth of the tourism industry and by virtue of this, triggers overall economic growth". Sebele [35] indicates that the concept of community development was introduced as an approach to rural development in the 1950s and 1960s. This approach calls for the more active involvement of locals in development issues. In the same vein, tourism literature since the 1980s has advocated the inclusion and involvement of local communities in tourism as local residents have been identified as being instrumental in sustaining the product [36]. Furthermore, Tosun [3] asserts that apart from being instrumental in tourism sustainability, community participation also ensures that a number of benefits accrue from tourism, namely: employment opportunities for local people, positive local attitudes, conservation of local resources and physical development within the community.

It is evident from the above that there is a considerable overlap between community tourism, sustainable tourism and sustainable development hence the need to explore a strategy that would ensure that local communities benefit from all three.

\section{Methodology}

The quantitative research paradigm was used in this study, hence the development of a questionnaire to collect primary data from the respondents. The questionnaire consisted of forty questions aimed at assessing the biographical data of the respondents in section "A", their perceptions of various impacts of tourism in their community in section "B" and lastly their attachment to the community in section " $\mathrm{C}$ ". These questions were modeled on the characteristics and benefits of community based tourism [37], and modified to suit the specific conditions of the Soshanguve community. The questionnaire covered three main areas of tourism impacts: economic, environmental and socio-cultural.

Data collection lasted two weeks, from 27 March 2012 to 10 April 2012. A total of two hundred questionnaires were handed out and 114 usable responses were returned giving a collection rate of 57 percent. Community members with an interest in tourism (owning, operating or working in tourism businesses) and other tourism stakeholders were specifically targeted for the data collection because it was presumed they would have a greater understanding of the issues raised and therefore provide more meaningful responses to the questions posed. The respondents were requested to score their perceptions on a five points likert scale from strongly disagree, disagree, neutral, agree to strongly agree. The descriptive statistics provided by the respondents were then captured on a spread sheet and evaluated using the SPSS 17.0 for windows program.

\section{Findings}

\section{Profile of the respondents}

The first striking element in the respondents profile was the fact that male respondents constituted 77 percent while 23 percent were females. This is contrary to the general perception that females make up the majority in the small business sector in tourism. Soshanguve is a predominantly black inhabited area so the racial composition of the respondents was not surprising with blacks' constituting 81 percent, coloureds' at 14 percent and whites' at 5 percent. Most of the respondents (43 percent) were between the ages of 20-29, with the 30-39 age groups coming in next at 33 percent and only 2 percent of the respondents over the age of 60 . This is quite positive news for growth in the industry as 
one would hope that the youth will mature and bring quality in to the tourism industry. This positive perception is further supported by the fact 68 percent of the respondents hold either a University degree or Diploma while only 5 percent have schooled below grade 7.71 percent of the respondents either own or work in tourism related businesses and 30 percent of these are the accommodation sector, 21 percent in tour guiding, 17 percent in transport and 11 percent in entertainment.

\section{Tourism impacts on the community}

It is important here to reiterate the three broad areas in which this study set out to evaluate the contribution of tourism to development in the community of Soshanguve, namely: economic, environmental and socio-cultural. The objective being to ensure the sustainable development imperative. These three main areas were further split into twenty eight easily identifiable action areas in which respondents could possibly observe change, with seven additional questions collecting biographical data and five focusing on the community attachment of respondents. The following is a report of findings regarding the respondents' observation of change (positive, negative or neutral) on specific issues raised.

44 percent of respondents agree that tourism is their primary source of income while 27 percent employ one or more people in their tourism businesses and 13 percent say they have received government support in running their businesses. On the other hand, while most respondents ( 54 percent) affirm that they have not received any assistance from government, very few (16 percent) disagree that tourism has increased job opportunities in their community. On whether tourism has attracted more investment into the Soshanguve community, 48 percent of the respondents agreed and 45 percent also agreed that tourism has contributed to improvements in basic facilities such as water, electricity and transport. Even though few respondents (15 and 13 percent respectively) disagreed with the foregoing, many respondents ( 37 and 42 percent respectively) were not sure and so remained neutral. In the final set of questions regarding economic impacts, respondents were asked to comment on whether tourism had encouraged local people to start their own businesses, if tourists spend money in their community and if they were any leakages from the local economy. 46 percent agreed that local businesses had sprung up due to tourism demand while 16 percent disagreed and 38 percent were neutral. 43 percent of the respondents agreed that tourists spend money in their community while 38 percent agreed that most benefits from tourism leaked out of the local economy. A general observation on the economic impacts expressed by the respondents is that the Soshanguve community has benefited from tourism.

The next set of questions focused on the socio-cultural impacts that have accrued from tourism development. Asked whether tourism has made them more proud of their culture, 34 percent disagreed while 17 percent agreed and 53 percent were not sure and so expressed a neutral opinion. Only 2 percent of the respondents agreed that tourism has made their culture better known in South Africa, 4 percent agreed that tourism has increased friendliness among community members and 14 percent agreed that tourism has led to a greater understanding of their culture. In fact, most respondents were quite negative about any cultural benefits, with 78 percent disagreeing that tourism has given their culture more exposure in South Africa. The respondents also did not perceive any negative social problems emanating from tourism development. Only one respondent agreed that prostitution had increased in the community due to tourism and only 3 percent agreed that crime had increased as a result of tourism development. On the contrary, 80 percent disagreed with the prostitution question and 77 disagreed with the idea that crime had increased because of tourism. However, 34 percent agreed that tourism has given them an opportunity to learn about other cultures, 17 percent agreed that tourism has encouraged that creation of more places for recreation and entertainment and 15 percent that tourism has increased their feeling of security in the community. Most respondents (51, 50 and 49 percent respectively) were neutral on these issues. Asked if their motivation to take care of wild life has improved as a result of tourism development, 39 percent disagreed, 13 percent were agreed and 48 percent took a neutral stance. The final question on socio-cultural impacts asked if the respondents felt that tourism was influencing their way of life and if their culture was disappearing. 60 percent disagreed, 6 percent agreed and 34 percent were neutral. Over all, it is evident that the respondents do not perceive many socio-cultural benefits coming from tourism development in their community.

On the impacts of tourism on the community environment, most respondents (61 percent) were neutral as to whether tourism had motivated the planting of trees, 7 percent strongly agreed, 7 percent agreed while 25 percent disagreed. In the same vein, 18 percent of the respondents agreed that the collection of litter had improved as a result of tourists visiting the community, 29 percent disagreed and 53 percent were neutral. On the negative side, most respondents (64 percent) disagreed that tourism had damaged the environment and 34 percent disagreed that tourism had put a strain on electricity and water consumption. On the same issues, only 6 percent agreed that tourism had contributed to environmental degradation and 28 percent of the respondents agreed that tourism caused a strain on water and electricity consumption. 33 percent of the respondents agreed that tourism had encouraged the restoration of historical buildings and monuments while 29 percent disagreed and 38 percent were neutral. In general, the community perception on environmental impacts seems fairly balanced.

The last part of the questionnaire dealt with the degree of community attachment among the respondents. Here, 61 percent agreed that they feel comfortable living in the community, 63 percent agreed that they are interested in knowing what goes on in the community, 35 percent agreed that they would be sad if they had to move from the community and 76 percent of the respondents agreed that they would be willing to participate in community development projects. On the other hand, only 6 percent of the respondents disagreed with being comfortable in the community, 8 percent were not interested in knowing what goes on in the community, 34 percent would not be sad leaving the community and 6 percent of the respondents were not willing to take part in community development projects. The general perception here is that there is great sense of community attachment among the respondents.

\section{Conclusions}

The following conclusions can be drawn from the foregoing findings:

Evidence from the Soshanguve community suggests that community benefit from tourism is indeed a reality, not a myth. There appears to be some benefit accruing to community members, no matter how minimal, in all spheres of sustainable development (economic, socio-cultural and environmental).

Community members seem to identify more with economic benefits than with socio-cultural and environmental gains. This is probably because economic challenges are higher in their hierarchy of needs than both socio-cultural and environmental preservation. There 
is also the sense that community members want to participate in the tourism economy but do not have the means to do so as evidence from the perception that government support is inadequate.

One of the most striking observations about this study is the apparent sense of apathy expressed by the respondents regarding the socio-cultural impacts of tourism development in their community. Most respondents seem to express the view that while tourism has not contributed to any good; it has also not contributed to any ills such as crime and prostitution. Unlike with the other two areas (economics and environment) where many people expressed neutral opinions, respondents expressed strong views regarding the influence of tourism in the socio-cultural domain.

Another important observation concerns the perceptions of the respondents regarding the environmental impacts of tourism in their community. The high percentage of respondents taking a neutral stance on most of the questions is probably an indication of the lack of information and understanding of the issues raised.

It is also evident from this study that there is a bright future for tourism in the Soshanguve community considering the high percentage of young people involved and interested in the industry and the level of education of the respondents.

\section{Recommendations}

Even though there is acknowledgement from the community that tourism has had some positive impacts on their lives, there is hardly a 50 percent agreement in any of the areas under study. This is indicative that a lot still needs to be done to maximize benefits from tourism to the community. The following recommendations indicate what is required from various tourism stakeholders in order to optimize tourism benefits in the Soshanguve community.

\section{Government}

Government should take the lead in tourism development in the community if significant strides have to be made. Given the high level of unemployment and poverty in the community, and considering the potential of tourism to create jobs, government support will lead to high rewards. Government intervention could take the following ways:

- Provision of guidelines for tourism operations in the community. These guidelines are necessary to ensure that there is a basic compliance model to guard against abuse. This will assure sustainability and a future for the industry in the long term.

- Formulation of a structure for the industry. Even though, there already exists tourism business owners' association called "Soshanguve tourism forum" in the community, this needs to be strengthened by providing an incentive for business operators to belong to this association. Further structuring could take the form of clustering of various sectors in the community such as accommodation, traditional healers, art and crafts, tour operators, etc. This will further ensure control and efficient channeling of support.

- Investment incentives: Government could also put in place investment schemes to facilitate micro business start-up.

- Skills development programmes: Managing a tourism business usually requires specialized skills that many people tend to ignore. These skills are required in areas such as tour guiding, accommodation management and all other sectors in the industry. The government could set up short training programmes that would empower locals with the necessary skills.

- Tourism Information centers: The strategic importance of tourists' information services is usually under-estimated. But this is a one-stop center where visitors can find information on tourism facilities and services in the community. On the other hand, it provides businesses with the first point of marketing for their products and enables tourists to spend more due to the easy access to product information.

- Security: The high incidences of crime or perceptions of these, particularly in the townships like Soshanguve seriously inhibits tourism growth and so government intervention in terms of police visibility and swiftness in combating crime would go a long way to encourage more tourists to feel at ease and enjoy community tourism.

\section{Community members}

- Entrepreneurial skills: In order to foster tourism in local communities and maximize benefits, community members posses the necessary entrepreneurial skills, be prepared to take risks and spot gaps in the tourism supply chain. Without these qualities, tourism might grow in the communities but would hardly benefit the community members.

- Recognizing the need for empowerment and information: It is also recommended that for residents of the Soshanguve community to maximize benefits from tourism, they have to empower themselves with the necessary skills required to work or manage tourism services. This is because tourism is a global industry and maintaining high quality standards is critical encouraging clients to return to the destination.

- Collaboration: This study further recommends that community members recognize the need for collaboration both within the community and with other stakeholders outside the community.

- Service quality: It is also important to draw the attention of the community members involved in tourism to the necessity for the quality of the products offered to be international competitive. Tourism is a global industry and it is essential that the destination offers value for money. This may necessitate a variation of the product offering so that clients do not cover long distances just to enjoy a few services.

- Tourism impact awareness: It is possible that most of the neutral opinions expressed by the respondents were merely due to lack of proper understanding of the tourism impacts mentioned. This necessitates that the community members educate themselves on the various impacts (positive and negative) of tourism development. This will enable to seek to mitigate the negative impacts and strive to capitalize on the positive impacts.

\section{Pressure groups (Non-governmental organisations)}

- Fair trade: NGOs that strive to achieve fair trade in tourism should ensure that weaker groups in the industry are not marginalized.

- Environmental groups: Even though most tourism resources are environmentally based, it is essential to draw the attention 
of communities using tourism as a tool for development to the fact that unregulated tourism can hurt the environment. The protection of both the flora and fauna is indispensable to the sustainability of tourism.

\section{The role of Big Business}

- Investment in capital-intensive projects such as shopping malls and other services. Businesses that are already well-known around the world should invest in local communities like Soshanguve in order to draw global attention to their product offering.

- Big businesses could also form partnerships with local companies so as to initiate them into the global arena and familiarize them with the global business environment. Mentorship programmes could also be introduced for small operators to learn the secrets of the business.

\section{Tourists}

- Acceptance of the product: For tourism to be sustainable in local communities such as Soshanguve, it is important for tourists to accept the products offered.

\section{References}

1. Lee TH (2012) Influence analysis of community resident support for sustainable tourism development. Tourism Management 34: 37-46.

2. Eagles PFJ, Mccool SF, Haynes CF (2002) Sustainable tourism in protected areas: Guidelines for planning and management, Gland, Switzerland: International Union for the conservation of nature.

3. Tosun C (2006) Expected nature of community participation in tourism development. Tourism Management 27: 493-504.

4. Inskeep E (1994) National and regional tourism planning. In A World Tourism Organization (WTO) Publication. London, UK: Routledge.

5. Nunkoo R (2011) Developing a community support model for tourism. Annals of Tourism Research 38: 964-988.

6. Gursoy D, Chi CG, Dyer P (2010) Local's attitudes toward mass and alternative tourism: The case of Sunshine coast, Australia. Journal of Travel Research 49: 381-394

7. Gursoy D, Rutherford DG (2004) Host attitudes toward tourism: An improved structural model. Annals of Tourism Research 31: 495-516.

8. Gursoy D, Jurowski C, Uysal M (2002) Resident attitudes: A structural modeling approach. Annals of Tourism Research 29: 79-105.

9. Jurowski C, Uysal M, Williams DR (1997) A theoretical analysis of host community resident reactions to tourism. Journal of Travel Research 36: 3-11.

10. Wattanakuljarus A, Coxhead I (2008) Is tourism-based development good for the poor? A general equilibrium analysis for Thailand. Journal of Policy Modeling 30: 929-955.

11. Lee CC, Chang CP (2008) Tourism development and economic growth: A closer look at panels. Tourism Management 29: 180-192.

12. World Travel and Tourism Council (2012) Travel and Tourism Economic impact 2012: South Africa.

13. World Travel and Tourism Council (2012) Travel and Tourism: Economic impact 2012: London, UK.

14. South Africa (1995) The rural development strategy of the government of national unity. A discussion document.

15. Kepe T (1998) Land reform and agrarian change in Southern Africa: An occasional paper. School of government: University of the Western Cape.

16. Rogerson CM, Visser G (2004) Tourism and development issues in contemporary South Africa. 2-25. Pretoria: Africa Institute of South Africa.

17. Department of Environmental Affairs and Tourism (1996) The development and promotion of tourism in South Africa. Government of South Africa.
18. Department of Environmental Affairs and Tourism (1998) Tourism in GEAR development strategy 1999-2000. Pretoria: RSA.

19. Viljoen J, Tlabela K (2007) Rural tourism development in South Africa: Trends and challenges. Human Sciences Research Council Press.

20. Department of Environmental Affairs and Tourism (2002) Responsible tourism handbook: A guide to good practice for tourism operators. Government of South Africa.

21. Goudie SC, Khan F, Kilian D (1999) Transforming tourism: black empowerment heritage and identity beyond apartheid. South African Geographical Journal 81 22-31.

22. Nxumalo $M$ (2003) Challenges facing black entrepreneurs in the South African tourism industry: A study on bed and breakfast establishments. Unpublished MA research report, University of the Witwatersrand, Johannesburg.

23. Rogerson CM (2004) Transforming South African tourism: the emerging blackowned bed and breakfast economy. GeoJournal 60: 273-281.

24. Scheyvens R (2002) Tourism for development: Empowering communities Prentice Hall, USA.

25. GPS Architects (2007) Product development for Soshanguve as a unique tourism destination. Tourism department: City of Tshwane Metropolitan Municipality.

26. Gauteng Tourism Authority (GTA) (2011) Annual Report 2010/2011.

27. Hall CM (2008) Tourism planning: Policies, processes and relationships. (2ndedn), Edinburgh Gate, UK: Pearson.

28. Cooper C, Fletcher J, Fyall A, Gilbert D, Wanhill S (2008) Tourism: Principles and practice. (3rdedn), Edinburgh Gate, UK: Pearson Education Limited.

29. Spenceley A (2008) Responsible tourism: critical issues for conservation and development. London, UK: Earthscan.

30. Choi HC, Sirakaya E (2006) Sustainability Indicators for managing community tourism. Tourism Management 27: 1274-1289.

31. World Commission on Environment and Development (1987) Our common future, 1987. Oxford University, UK.

32. Keyser H (2009) Developing tourism in South Africa: towards competitive destinations. (2ndedn), Cape Town, South Africa: Oxford University Press.

33. Butler RW (1991) Tourism, Environment, and Sustainable Development Environmental Conservation 18: 201-209.

34. World Tourism Organization (2004) Sustainable development of tourism Conceptual definition. Madrid: World Tourism Organisation.

35. Sebele LS (2010) Community-based tourism ventures, benefits and challenges: khama rhino sanctuary trust, central district, Botswana. Tourism Management 31:136-146.

36. Hardy A, Beeton RJS, Pearson L (2002) Sustainable tourism: an overview of the concept and its position in relation to conceptualisations in tourism. Journal of Sustainable Tourism 10: 475-496.

37. Simpson MC (2008) Community benefit from tourism initiatives: A conceptual oxymoron? Tourism Management 29: 1-18. 